\title{
Testosterone Biosynthesis Deficiency
}

National Cancer Institute

\section{Source}

National Cancer Institute. Testosterone Biosynthesis Deficiency. NCI Thesaurus. Code C102987.

Inadequate production of circulating testosterone. 